\title{
Influence of Write Head Width in Discrete Track Recording
}

\author{
K. Nishikawa, H. Teguri, M. Ohtake, M. Hashima*, A. Iida, S. Eguchi, and A. Tanaka \\ Storage Laboratories, Fujitsu Laboratories Ltd.,10-1 Morinosato-wakamiya, Atsugi, Kanagawa 243-0197, Japan \\ *Business Incubation Laboratories, Fujitsu Laboratories Ltd.,10-1 Morinosato-wakamiya, Atsugi, Kanagawa 243-0197, Japan
}

\begin{abstract}
To investigate the influence of the variation of the write track width in the discrete track recording, we calculated the off-track capability (OTC) of the write/read head using Landau-Lifshitz-Gilbert micromagnetic simulations. Recently, the OTC has become increasingly important in the system design of the hard disk drive (HDD). As for the write head, it is a serious problem that the write track width varies significantly in the manufacturing processes. In the simulations, we evaluated the OTC of the wite/read head as a function of the write track width on both conventional and discrete track media from the viewpoint of the signal-to-noise ratio (SNR). As a result, we found that the OTC of write/read head on discrete track media was superior to that of conventional media for variations of the write track width.
\end{abstract}

Key words: micromagnetics simulation, write track width, discrete track medium, off-track capability, signal-to-noise ratio

\section{ディスクリートトラック記録方式における記録トラック幅ばらつきの影響}

\author{
西川清, 手操弘典, 大竹雅哉, 橋間正芳 *, 飯田安津夫, 江口 伸, 田中厚志 \\ 株式会社富士通研究所 ストレージ研究所, 神奈川県厚木市森の里若宮 $10-1$ ( テ243-0197) \\ *株式会社富士通研究所 ビジネスインキュベーション研究所, 神奈川県厚木市森の里若宮 $10-1$ (テ243-0197)
}

\section{1 はじめに}

ハードディスク装置 $(\mathrm{HDD})$ ) が垂直記録方式へと移り, 大容 量化・高密度化へ流れは留まることを知らない.ヘッド・媒体 間の物理的スペーシングが究極に狭められた状況において, 高 密度記録を実現していくためには, 数多くの個別の技術的課題 を克服するのは勿論のこと, ヘッド, 媒体, および装置のそれ ぞれのマージンの最適な配分が重要となってきている.ヘッド に関して言えば, トラック密度の向上に伴い, 記録トラック幅 （記録へッドにおける主磁極のトラック幅方向の物理的寸法, 以下同様）が縮小し，ヘッド磁界強度は低下する. ある一定の 必要ヘッド磁界を確保するため, 狭い記録トラック幅を精度良 く製造上コントロールし，その記録トラック幅ばらつきを抑え ていくことが，ハードディスク装置を量産していく上でますま す重要となってきている. 現状, 最新の微細加工技術を用いた 場合でも, 目標とする記録トラック幅に対して, 標準偏差でお よそ $10 \%$ 程度のばらつきが生じてしまう。

一方, 記録媒体においては, サイドイレーズの抑制, および グラニュラ粒子サイズ縮小に対する熱安定性の確保から, 媒体 異方性磁界 $\left(H_{k}\right)$ を記録可能な範囲で, ぎりぎりまで高くする 傾向にある. したがって, 目標とする寸法よりも記録トラック 幅が狭く出来上がった場合に記録し難くなり, 媒体磁化の信号 とノイズの比 ( SNR ) を十分に確保できなくなる可能性があ る. 逆に, 記録トラック幅が広く出来上がった場合には, 自己 トラックを十分に飽和記録できたとしても，隣接トラックへの 漏孔磁界の増大により, 許容範囲以上のサイドイレーズが生 じてしまう。記録へッドに抢けるトラック幅の微細加工限界,
ヘッド漏れ磁界によるサイドイレーズ, クロストークなどの問 題が顕在化してきており, 従来の改良手法による面記録密度の 向上に限界が見えつつある.

本稿では, 物理的に溝を形成することで, サイドイレーズ, およびクロストークなどに対する改善が期待されているディス クリートトラック記録方式 ${ }^{1-9)}$ に着目し，ディスクリート媒体 と従来の連続媒体において, 記録トラック幅のばらつきが与え る影響について, マイクロマグネティックシミュレーションに よる比較検討をおこなった.

\section{2 計算モデル}

三次元有限要素法で計算した記録ヘッド磁界分布を用い, LLG 方程式に基づいたマイクロマグネティックス法を用いた シミュレーションにより, 媒体上に記録される磁化状態を求 めた.

記録へッドには, トレーリングシールドタイプのヘッド 10) を用い, 記録トラック幅 $70 \sim 110 \mathrm{~nm}$, 駆動コイル電流 (起磁 力： MMF ) 0.1 および $0.2 \mathrm{AT}$ をパラメータに, 主磁極の飽和 磁束密度を $2.3 \mathrm{~T}$ として, ヘッド磁界計算をおこなった. 裏打 ち層 ( SUL ) の膜厚を $60 \mathrm{~nm}$, 飽和磁束密度を $1.5 \mathrm{~T}$, 記録へッ ドから媒体記録層表面までの磁気スペーシングを $8.5 \mathrm{~nm}$ とし た. Fig.1に, 記録磁化シミュレーションに取り込んだへッド 磁界分布を示しており，媒体の膜厚方向に，媒体表面から 8.75 $\mathrm{nm}$ (記録層膜厚の $1 / 2$ ) 入った位置におけるトラックセンター のプロファイルを示す．縦軸は, Stoner-Wohlfarth モデルに基 づいた有効磁界（以下，すべて有効磁界）で表しており，記録 


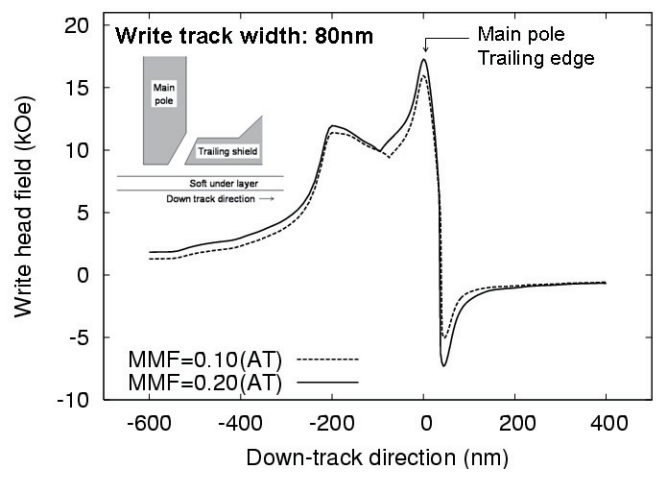

Fig. 1 Write head field distribution along the down-track direction, where the write track width is $80 \mathrm{~nm}$ and the magnetomotive forces (MMF) are 0.1 and 0.2 AT.

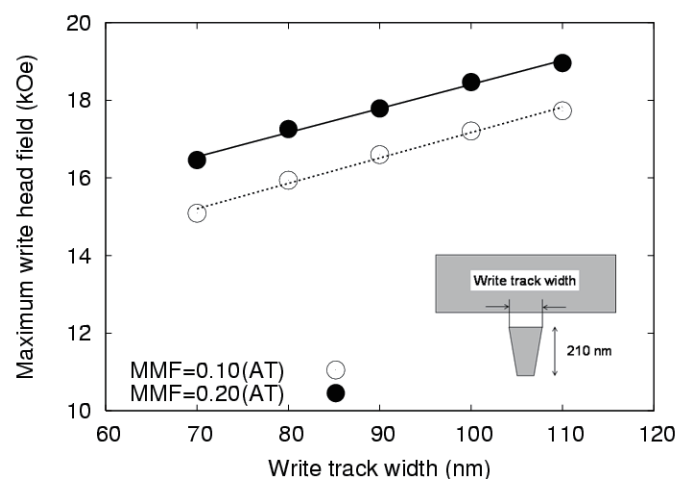

Fig. 2 Maximum write head field as a function of the write track width, where the MMF are 0.1 and 0.2 AT.

トラック幅 $80 \mathrm{~nm}$, 起磁力 0.2 AT のとき, トレーリングシー ルドエッジ近傍で, $17.3 \mathrm{kOe}$ の最大ヘッド磁界強度が得られ ている. Fig.2 には, 横軸に記録トラック幅（図中では Write track width, 以下同様) をとり, 縦軸に最大へッド磁界強度を プロットした図を示している. Fig.2 の最大へッド磁界強度の 記録トラック幅依存性より, 起磁力が $0.2 \Rightarrow 0.1$ AT に半減した 場合に，磁界強度は一様に約 $1.3 \mathrm{kOe}$ 減少し，また記録トラッ ク幅が $10 \mathrm{~nm}$ 変動すると, 磁界強度が約 $0.8 \mathrm{kOe}$ 変化する.

一方, 記録磁化シミュレーションにおける記録媒体のパラ メータとしては, 平均粒径サイズ $7.3 \mathrm{~nm}$, 記録層の膜厚 17.5 $\mathrm{nm}$, 異方性磁界 $\left(H_{k}\right) 13.5 \mathrm{kOe}$, 飽和磁化 $\left(M_{s}\right) 500 \mathrm{emu} / \mathrm{cm}^{3}$, 粒子間の交換結合定数 $\left(A^{*}\right) 0.5 \times 10^{-7} \mathrm{erg} / \mathrm{cm}$ としたボロノイ 形状粒子による単層膜媒体を用いて検討をおこなった。なお, 各パラメータについては，次のようにばらつきを与えた。平均 粒径サイズについては，平均（ノミナル）值に対して $15 \%$ の 標準偏差をもつ対数正規分布, 異方性磁界 $\left(H_{k}\right)$ および 飽和磁 化 $\left(M_{s}\right)$ については, ノミナル值に対して, それぞれ独立に 8 $\%, 10 \%$ の標準偏差をもつ正規分布とした． $H_{k}$ 容易軸方向の 分散角度については $1.3^{\circ}$ とした。 また, ディスククリート媒 体のモデル化に際しては，本稿では，線記録密度 1550 kFCI と した $400 \mathrm{Gbpsi}$ の面記録密度をターゲットに, 従来の連続媒体 との比較検討をおこなうため, トラック密度 258 kTPI ( トラッ
クピッチ : $98 \mathrm{~nm}$ ) に対して, ランド幅を約 $60 \mathrm{~nm}$ (トラック ピッチの約 $60 \%$ )，溝幅を約 $40 \mathrm{~nm}$ とした。

再生 ( SNR) 計算では，再生ヘッドの物理的な幅を $60 \mathrm{~nm}$ と し, 3 次元的に与えたヘッド感度プロファイルを用いて，記録 磁化シミュレーションにより求めた媒体磁化状態との畳み达 みにより媒体 SNR を見積もった。本稿における媒体 SNR は, 信号抽びノイズの両者を $\mathrm{rms}$ 值で求め, その比から求めて いる.

\section{3 再生ヘッドのオフトラック特性}

Fig.3 に, 従来の連続媒体とディスクリート媒体に対して, 記録トラック幅 $80 \mathrm{~nm}$ の記録ヘッドを用い，単一周波数の信 号で記録を扢こなったシミュレーションによる磁化状態を示 す. Fig.3 では, 記録トラック周囲の磁化から静磁界の影響を 平均化するため, $\mathrm{AC}$ イレーズした状態において, はじめに, センタートラックに高密度 ( $775 \mathrm{kFCI}$ ) で記録をおこない, さ らにその左右両側に，センタートラックから 1 トラックピッチ ( $98 \mathrm{~nm}$ ) 離して低密度 ( $194 \mathrm{kFCI})$ で記録をおこなっている. HDD 装置評価では，信号をランダムに記録したパターンにお ける媒体 SNR でテストを扢なっているが，装置の運用上， 仕様にある最高線記録密度の単一周波数の信号が繰り返し並ぶ ようなことはほとんどないこと，またシミュレーション上，ラ ンダムに記録した信号の媒体 SNR が精度良く見積もれないと いう理由から，本稿では，センタートラックにできる限り高密

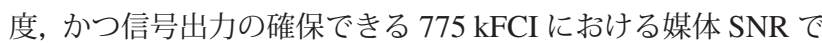
議論を抽なっている.

Fig.4 には, Fig.3の 3 本のトラックを記録した磁化状態か ら算出した媒体 SNR のオフトラック特性の結果を, 従来の連 続媒体 (破線) とディスクリート媒体 (実線) との比較で示して いる. Fig.4 の媒体 SNR オフトラック特性の結果より, 連続 媒体のトラックセンターにおける媒体 SNR は，ディスクリー 卜媒体に比べて約 $1.5 \mathrm{~dB}$ 高いことがわかる. しかしながら, 再生へッドをオフトラックさせた場合, 連続媒体における媒 体 SNR は急激に低下しており，例えば，所定のビットエラー レートが確保できる媒体 SNR を $12 \mathrm{~dB}$ とした場合に, ディス クリート媒体は, 連続媒体に比べて, オフトラックマージンが $39 \mathrm{~nm}$ から $65 \mathrm{~nm}$ に拡がることが読み取れる. したがって, 所 定のビットエラーレートに相当する媒体 SNR が確保できるな らば，ディスクリート媒体のほうが，連続媒体に比べて，才フ トラックマージンの点で優れている

\section{4 記録ヘッドのオフトラック特性}

Fig.5 左図に, 従来の連続媒体において, 記録へッドのトラッ ク幅を横軸にとり, センタートラックのみに高密度 ( $775 \mathrm{kFCI}$ ) で記録したときのトラックセンターにおける媒体 SNR ( 1 Track write ) と，さらにセンタートラックから左右両側に 1 ト ラックピッチ ( $98 \mathrm{~nm}$ ) 離して, 低密度 ( $194 \mathrm{kFCI}$ ) で記録し たときのトラックセンターの媒体 SNR ( 3 Track write ) とを プロットした図を示す。但し，トラックセンターにおける媒体 

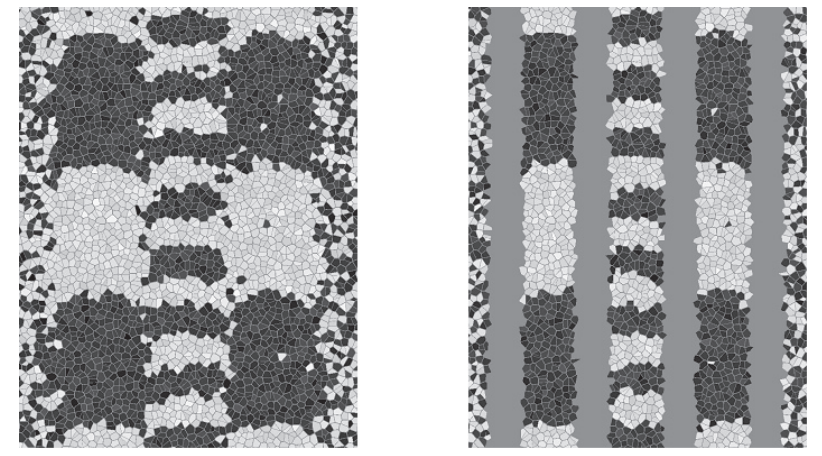

Fig. 3 Calculated magnetization pattern of (left) conventional medium and (right) discrete track medium using trailing shielded write head, where the write track width is $80 \mathrm{~nm}$ and the MMF is 0.2 AT.

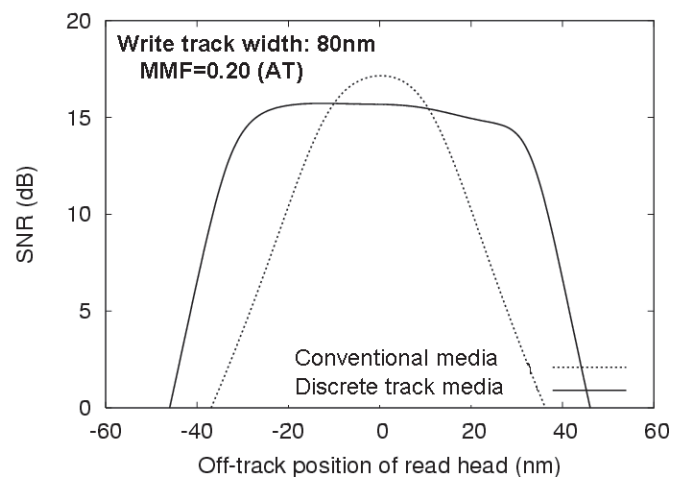

Fig. 4 SNR as a function of the off-track position of read head on conventional and the discrete track media.

SNR は, 物理的な幅 $60 \mathrm{~nm}$ の再生ヘッドが, トラックセンター にオントラックしたときの SNR 值を意味する. ディスクリー 卜媒体の場合について, 同様な計算をおこなつた結果について も, Fig.5 の右図に示している. Fig.5 左図の連続媒体の場合, センタートラックに 1 本のトラックのみを記録したときの媒体 SNR は, 記録トラック幅に比例して媒体 SNR は増大する. し かしながら, 3 本のトラックを記録した場合に, 媒体 SNR は, 記録トラック幅の増加にともない著しく低下し, 記録トラック 幅が $90 \mathrm{~nm}$ で, すでに媒体 SNR の劣化が見えはじめている.

一方, ディスクリート媒体の場合 ( Fig.5 右図参照), 記録卜 ラック幅が $110 \mathrm{~nm}$ の場合を除いては，1 本のトラックのみ記 録した場合と，3本のトラックを記録した場合で比較しても， トラックセンターにおける媒体 SNR はほとんど変化していな い. また, 記録トラック幅の増加に対しても, 記録トラック幅 100 nm まで媒体 SNR はほとんど劣化せず，ディスクリート媒 体のほうが, 記録トラック幅のばらつきに対して, 安定した記 録性能が確保できる可能性を示している. すなわち, 従来の連 続媒体は, 記録トラック幅が増加するにつれて, 隣接トラック 記録時のサイドイレーズやクロストークの影響を受けて, 媒体 SNR が劣化しやすいが, ディスクリート媒体では, 物理的に 溝を形成することによって, 隣接トラックから受ける影響が抑 制され, 記録トラック幅変動に対するマージンが拡大すること を示している.
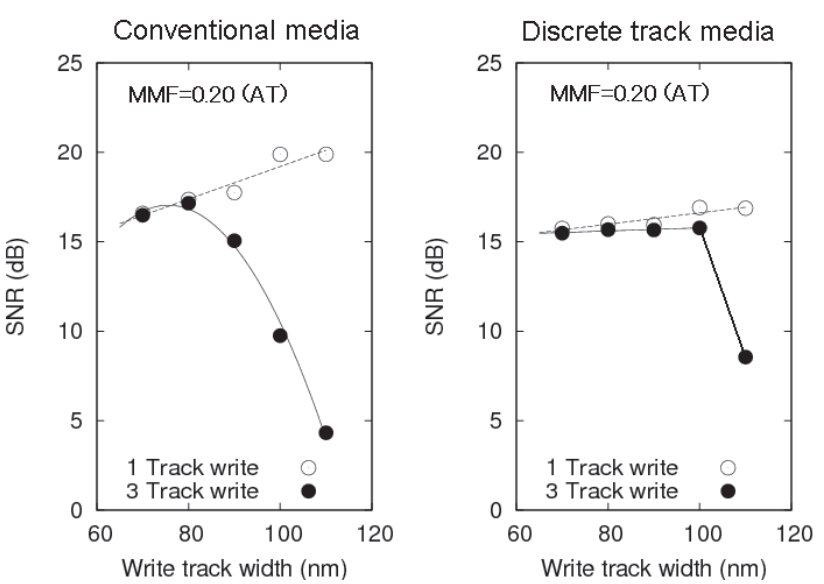

Fig. 5 SNR as a function of the write track width on (left) conventional and (right) discrete track media.

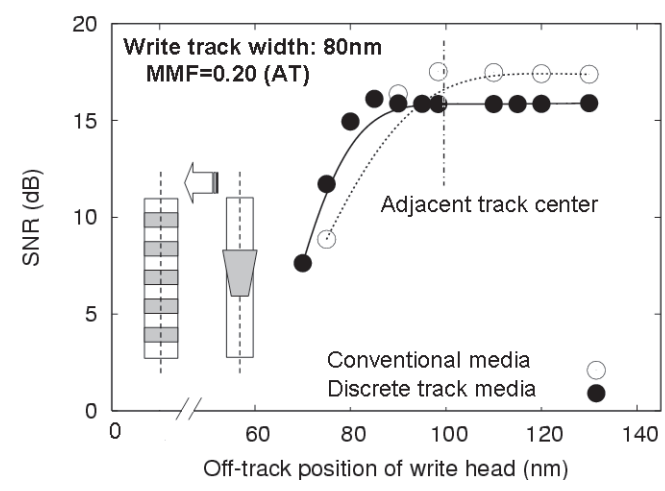

Fig. 6 SNR as a function of the off-track position of write head on conventional and discrete track media.

次に, Fig.6には, 連続媒体とディスクリート媒体において, トラックピッチを $98 \mathrm{~nm}$ に固定したまま, 記録トラック幅 80 $\mathrm{nm}$ の記録へッドを，ある一方向から隣接トラックのオフセッ 卜量を変えて, 記録をおこなった場合の媒体 SNR のふるまい を示している. Fig.6 は, 前述の Fig.3 と同様, AC イレーズ状 態を初期状態とし，センタートラックに，はじめ高密度 $(775$ $\mathrm{kFCI}$ ) の単一周波数の信号で記録をおこない, そのトラック のセンター位置を基準（ゼロ）とし, 片方の側から, 低密度 194 kFCI ) で記録をおこなっては, トラックセンターにおける 媒体 SNR を見積もることを繰り返しおこなった結果を示して いる．連続媒体の場合，記録へッドをトラックセンターから約 $100 \mathrm{~nm}$ まで近づけると, 媒体 SNR が劣化し始めるのに対し, ディスクリート媒体では, 約 $90 \mathrm{~nm}$ まで近づけても劣化は見ら れていない。 すなわち, ディスクリート媒体は, 物理的に溝を 形成しているために，隣接トラックからの影響を受け難くなつ ており, 片側からの寄せ書きに対して, 約 $10 \mathrm{~nm}$ オフトラック マージンが拡大することを示している．実際のドライブ評価と 同様, 左右両側から寄せ書きしてくる場合を考慮すると, ディ スクリート媒体のほうが, 約 $20 \mathrm{~nm}$ オフトラックマージンで 有利となってくる.

最後に，ディスクリート媒体に対し，記録ヘッドのトラック 


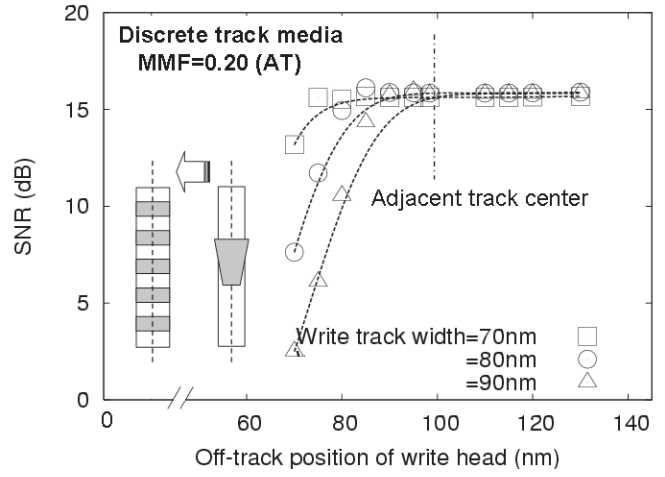

Fig. 7 SNR of discrete track media as a function of the off-track position of write head for various write track widths.

幅をパラメータにして, Fig.6 と同様に, 寄せ書きした結果を Fig.7 に示す. ディスクリート媒体において, 片側から寄せ書 きしてくる記録へッドが十分に離れた位置では, 媒体 SNR は 記録へッドのトラック幅に依らず，約 $15 \mathrm{~dB}$ 以上の安定した性 能が確保できている. 連続媒体の場合, トラック幅 $80 \mathrm{~nm}$ を 有する記録へッドを用いると，トラックセンター（基準）位置 から約 $100 \mathrm{~nm}$ まで近づけると，媒体 SNR が劣化する（Fig.6 参照）のに対し，ディスクリート媒体の場合，トラック幅 90 $\mathrm{nm}$ を有する記録ヘッドで, トラックセンター（基準）位置か ら約 $100 \mathrm{~nm}$ 付近まで近づけてきても，媒体 SNR の劣化は全 く見られていない. したがって，ディスクリート媒体では，従 来の連続媒体に比べて, 約 $10 \mathrm{~nm}$ 程度増大した記録トラック 幅でも許容できることを示唆している.

以上より, ディスクリート媒体と組み合わせることにより, 記録および再生のオフトラックマージンは拡大し，ヘッドの製 造工程における記録トラック幅のばらつきを, $80 \pm 10 \mathrm{~nm}$ で 許した場合でも，媒体 SNR 值の変動や劣化は見られず，想定 している 400 Gbpsi ( 258 kTPI × $1550 \mathrm{kFCI}$ ) 仕様を, 余裕を もって満たすことができる.

\section{5 まとめ}

ディスクリート媒体と従来の連続媒体において，記録トラッ ク幅のばらつきが与える影響について，マイクロマグネティッ クシミュレーションによる比較検討をおこなった. シミュレー ションの結果, 従来の連続媒体では, 想定しているトラック ピッチ $98 \mathrm{~nm}$ ( トラック密度: 258 kTPI ) において, 記録トラッ ク幅のばらつきに対するマージンが数 $\mathrm{nm}$ 程度しかないのに対 して, ディスクリート媒体では, 左右両側からの寄せ書きに対 し, 約 $20 \mathrm{~nm}$ オフトラックマージンが拡大する. ヘッド製造 工程における記録トラック幅に $80 \pm 10 \mathrm{~nm}$ のばらつきが生じ た場合でも，媒体 SNR の変動や劣化は見られない。すなわち， 物理的に溝を形成したディスクリート媒体を用いることによ り, 従来の連続媒体に比べて, 記録トラック幅ばらつきに対す る媒体 SNR 特性の変動や劣化が抑えられ，記録および再生の オフトラックマージンは拡大する. ディスクリート媒体の適用 により, 歩留まり良く HDD 装置が製造できるようになる.

謝辞 本研究を進めるにあたり, 株式会社富士通研究所スト レージ研究所, 富士通株式会社 ストレージプロダクト事業本 部の各関係部門の皆様には, 多大なご協力及び適切なご助言を いただいたことに深く感謝いたします。

\section{References}

1) S. E. Lambert, I. L. Sanders, A. M. Patlach, and M. T. Krounbi: IEEE Trans. Magn., MAG-23, 3690 (1987).

2) D. Wachenschwanz, W. Jiang, E. Roddick, A. Homola, P. Dorsey, B. Harper, D. Treves, and C. Bajorek: IEEE Trans. Magn., 41, 670 (2005).

3) S. Haratani, A. Kaizu, and I. Sato: IEEE Trans. Magn., 39, 3220 (2003).

4) Y. Soeno, M. Moriya, A. Kaizu, and M. Takai: IEEE Trans. Magn., 41, 3220 (2005).

5) A. Kaizu, Y. Soeno, M. Takai, K. Tagami, and I. Sato: IEEE Trans. Magn., 42, 3220 (2006).

6) S. J. Greaves, H. Muraoka, and Y. Kanai: IEEE Trans. Magn., 42 , 2408 (2006)

7) S. J. Greaves, H. Muraoka, and Y. Kanai: J. Appl. Pys., 99, 08F903 (2006).

8) X. Che, Y. Tang, H. Lee, S. Zhang, K. Moon, N. Kim, S. Hong, N. Takahashi, M. Moneck, and J. Zhu: IEEE Trans. Magn., 43, 2292 (2007).

9) Y. Tang, X. Che, H. Lee, and J Zhu: IEEE Trans. Magn., 44, 4780 (2008).

10) M. L. Mallary: US Patent A.P., US 4656546 (1987).

2009 年 10 月 21 日受理, 2010 年 2 月 24 日採録 